\title{
REVIEW
}

\section{The lung in the antiphospholipid syndrome}

\author{
G Espinosa, R Cervera, J Font, R A Asherson
}

Ann Rheum Dis 2002;61:195-198

Patients with antiphospholipid syndrome (APS) may develop a broad spectrum of pulmonary disease. Pulmonary thromboembolism and pulmonary hypertension are the most common complications, but microvascular pulmonary thrombosis, pulmonary capillaritis, and alveolar haemorrhage have also been reported. Clinicians should seriously consider these types of vascular injury when evaluating patients with APS who present with dyspnoea, fever, and infiltrates on chest radiography.

See end of article for authors' affiliations

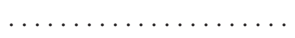

Correspondence to: Dr R Cervera, Servei de Malalties Autoimmunes, Hospital Clínic, Villarroel, 170. 08036 Barcelona, Catalonia, Spain rcervera@clinic.ub.es

Accepted 24 September 2001
T he antiphospholipid syndrome (APS) is diagnosed when arterial or venous thrombosis, or recurrent miscarriages occur in a subject in whom laboratory tests for antiphospholipid antibodies (aPL) (anticardiolipin antibodies (aCL), or lupus anticoagulant (LAC), or both) are positive. ${ }^{1}$ Because thrombotic disease, miscarriage, and transient aPL positivity are not uncommon events, persistence of aPL positivity must be demonstrated and all other causes and contributory factors considered. In each patient this syndrome is considered primary, if unassociated with any other underlying disease, ${ }^{2}$ or secondary, if it appears in association with other autoimmune disorders, mainly systemic lupus erythematosus (SLE) but also with other conditions-for example, carcinoma, vasculitic syndromes, drug administration, etc. ${ }^{3}$ An international workshop recently reported a consensus statement on classification criteria for APS. ${ }^{4}$

Pulmonary manifestations, including pulmonary embolism and infarction, ${ }^{5}$ pulmonary hypertension, ${ }^{67}$ adult respiratory distress syndrome (ARDS), ${ }^{8}$ intra-alveolar haemorrhage, primary thrombosis of lung vessels, both large ${ }^{10}$ and small," as well as pulmonary capillaritis, may be associated with this syndrome in both the primary and secondary forms. ${ }^{12}$ Less commonly, a postpartum syndrome ${ }^{13}$ and fibrosing alveolitis ${ }^{14}$ associated with APS have been described. Obviously, many of these manifestations are interrelated and they may occur simultaneously in the same patient. ${ }^{15}$

\section{PULMONARY MANIFESTATIONS IN THE APS} Pulmonary embolism and infarction

The first major pulmonary complication to be recorded was pulmonary thromboembolic disease, which does not differ clinically from "ordinary" emboli, a disease in aPL negative patients. It constitutes the most common pulmonary manifestation of the APS and may be the first manifestation of the disease. ${ }^{5}$ Recurrent pulmonary emboli may give rise to pulmonary hypertension ${ }^{16}$ that may, unusually, in severe cases, be accompanied by isolated tricuspid valve insufficiency. ${ }^{10}{ }^{17}$

$$
\begin{aligned}
& \text { "Pulmonary embolism may be the first } \\
& \text { manifestation of APS" }
\end{aligned}
$$

Management of the acute thrombotic event is the same in patients with APS as in the general population. Patients require anticoagulation treatment with heparin followed by warfarin. Long term (possibly lifelong) oral anticoagulation is the optimum prophylactic treatment for recurrent thrombosis and appears to be more effective than antiaggregants. ${ }^{18}{ }^{19}$ Nevertheless, the recommended therapeutic international normalised ratio (INR) remains controversial. Some authors have reported that high intensity anticoagulation $(I N R>3)$ is more effective than low intensity anticoagulation $(\mathrm{INR}<3)$ in preventing recurrences, although the risk of haemorrhage complications is higher. ${ }^{18}{ }^{20}$ Multicentre prospective trials are needed to determine the optimal range of anticoagulation without increasing this bleeding risk. While awaiting these results, we recommend that an INR ranging between 2.5 and 3.5 is maintained. ${ }^{19}$

\section{Pulmonary hypertension}

The prevalence of pulmonary hypertension in APS associated with SLE and the primary APS has been estimated to be between $1.8 \%$ and $3.5 \%$, respectively. ${ }^{21}$ The development of pulmonary hypertension in APS may result from various causes. Recurrent pulmonary embolism is assumed to be the leading cause of pulmonary hypertension in APS. ${ }^{6}$ The prevalence of aPL in patients with chronic thromboembolic pulmonary hypertension varies between $10 \%^{22} 23$ and $20 \%{ }^{24}$ It is likely that chronic thromboembolic pulmonary hypertension after pulmonary thromboembolism develops more frequently in the presence of aPL. The association of pulmonary hypertension with aPL was first reported in 1983. ${ }^{25}$ Since this original communication, there have been many other reports describing this association, not only with SLE $^{26-30}$ but also in the primary APS. ${ }^{2}{ }^{31-34}$ In a prospective analysis of 500 patients with SLE, a statistically significant

Abbreviations: $a C L$, anticardiolipin antibodies; $a \mathrm{PL}$, antiphospholipid antibodies; APS, antiphospholipid syndrome; ARDS, adult respiratory distress syndrome; INR, international normalised ratio; LAC, lupus anticoagulant; SLE, systemic lupus erythematosus 
association between pulmonary hypertension and the presence of IgA aCL above 2SD has been described. ${ }^{35}$ An extended study performed on 667 patients with SLE confirmed the association of pulmonary hypertension with aPL, but the criteria used were not precisely defined. ${ }^{36}$ On the other hand, several studies have failed to show any association with pulmonary hypertension and the presence of aPL. ${ }^{37}{ }^{38}$ Several cases of "primary" (non-thromboembolic) pulmonary hypertension complicating primary APS have been described. ${ }^{27} 3439$ Luchi et al interpreted their case as the coexistence of pulmonary thrombosis with primary pulmonary hypertension, ${ }^{7}$ which would explain the plexogenic lesions found on lung biopsy. However, plexogenic lesions are also known to occur in chronic thromboembolic pulmonary hypertension.

The role of aPL in the pathophysiology of "unexplained" primary pulmonary hypertension is unclear at this time. In a group of 30 patients with idiopathic (non-SLE) primary pulmonary hypertension, four had aPL (LAC in two and low IgG aCL in three).$^{40}$ Conversely, a recent study described a higher prevalence of aPL in thromboembolic pulmonary hypertension than in primary pulmonary hypertension. ${ }^{41}$ All forms of severe pulmonary hypertension may be complicated by superimposed in situ thrombosis, ${ }^{42}$ and the risk of categorising some patients with pulmonary hypertension as definite APS has been described. ${ }^{4}$ Other explanations might include a role for activated platelets; for an interaction between aPL and endothelial cells on the pulmonary vasculature, leading to vascular remodelling; or the implication of endothelin-1, a peptide that induces vasoconstriction and stimulates the proliferation of vascular muscle cells. High levels of endothelin-1 have been found in both plasma and lung tissue of patients with primary pulmonary hypertension ${ }^{43}$ and in plasma of patients with APS with arterial thrombosis. ${ }^{44}$ Portal hypertension $^{45}$ or pulmonary veno-occlusive disease, ${ }^{46}$ as mechanisms leading to pulmonary hypertension, may also occasionally be encountered with APS positivity.

\section{"The outcome in patients with pulmonary hypertension and APS is usually fatal"}

To manage pulmonary hypertension, chronic anticoagulation is needed in all cases to prevent the occurrence of new thrombotic events, ${ }^{47}$ and this seems to be particularly true for patients with APS. ${ }^{18}$ If pulmonary hypertension is secondary to recurrent thromboembolism, the placement of an inferior vena cava filter may be recommended ${ }^{48}$ In some patients with very severe disease, successful thromboendarterectomy has been performed..$^{10249}$ Other treatments are those used in primary pulmonary hypertension that is "unexplained" or associated with systemic autoimmune disease. According to the results of acute drug testing, patients are given vasodilators such as calcium channel blockers, but unfortunately only one third of patients respond to this vasodilator challenge. ${ }^{26}{ }^{50} \mathrm{In}$ severe cases, continuous intravenous prostacyclin infusion with a pump may be useful. ${ }^{51}$ Cyclophosphamide has also seemed to be beneficial in primary pulmonary hypertension associated with connective tissue disease, but there is no experience of this treatment in APS associated primary pulmonary hypertension. ${ }^{26}$ Finally, diverse surgical procedures (atrial septectomy and double lung, single lung, or heart-lung transplantation) in patients refractory to medical regimens have been described. The mortality remains high and, in general, the outcome in patients with pulmonary hypertension and APS is usually fatal, ${ }^{729}$ although a patient with primary APS and primary pulmonary hypertension with a survival since diagnosis of more than 20 years has been described. ${ }^{34}$

\section{Pulmonary arterial thrombosis}

In some patients the thrombotic obstruction occurs at the level of the large, elastic pulmonary arteries. Six patients with
APS and major pulmonary arterial thrombosis have been described up to the present time. ${ }^{702452}$ Five of them were treated with thromboendarterectomy, with this procedure being successful in four. A fatal outcome in the remaining patients was in fact expected given the severe clinical and haemodynamic abnormalities which were present. Despite these good results these patients should continue to receive long term oral anticoagulation treatment.

\section{Pulmonary microthrombosis}

Certain patients with APS present with widespread thrombotic occlusions affecting the small pulmonary arteries or alveolar capillary lumens. ${ }^{811} 121653$ Three of six patients showed isolated microthromboses on lung biopsy without evidence of pulmonary capillaritis or alveolar haemorrhage. ${ }^{11}{ }^{12} 16$ These three patients had been diagnosed previously as primary APS. Clinically, the first presented with fever, cough, mild haemoptysis, and shortness of breath at rest and at minimal exercise. Chest radiography showed bilateral patchy infiltrates. Pulse methylprednisolone was given followed by $50 \mathrm{mg}$ prednisone daily and heparin, and the patient's condition improved dramatically within days. The second patient presented with fever and pain in her left chest, showing a consolidation of the left lingula and a pleural effusion on chest radiography. Unfortunately, the treatment and evolution of the disease in this patient was not reported. The third patient presented with dyspnoea and pulmonary hypertension with involvement of tricuspid and mitral valves. His clinical course deteriorated progressively despite treatment with high dose steroids and continuous intravenous heparin, and he died of intractable cardiac failure. The remaining cases showed alveolar haemorrhage and pulmonary capillaritis on the lung biopsies, presenting with a clinical picture of ARDS. Two of these patients died, one of them despite receiving high dose steroids, heparin, aspirin, and azathioprine. The remaining patient improved gradually with the administration of IV pulses of methylprednisolone.

\section{Adult respiratory distress syndrome (ARDS)}

ARDS is an uncommon, devastating clinical syndrome of acute lung injury characterised by an acute onset, with arterial hypoxaemia refractory to treatment with supplemental oxygen. Radiographically, there are bilateral infiltrates which may be patchy or asymmetrical, and there may be accompanying pleural effusions. ${ }^{54} \mathrm{Up}$ to the present time, 27 patients with ARDS and the APS have been reported, ${ }^{83} 55-5821$ of them with catastrophic APS, ${ }^{58}$ with a mortality of $52 \%$, despite full anticoagulation treatment, high dose steroids, and immunosuppression. Histological examination of lung specimens disclosed extensive small vessel thromboses, intra-alveolar haemorrhage, hyaline membrane formation with or without pulmonary capillaritis. The mechanism of ARDS in APS is unclear. In the absence of inflammatory changes, an acute increase in hydrostatic pressure by an occluding embolus may cause exudation of fluid from blood vessels into the lung parenchyma. ${ }^{56}$ Pulmonary microembolism may cause vascular injury in the pulmonary circulation and increase the transport of proteins through the pulmonary microvascular barrier into the parenchyma. ${ }^{8}$ Management consists, in addition to anticoagulation, of high dose steroids, and occasionally, pulse cyclophosphamide and plasmapheresis.

\section{Intra-alveolar pulmonary haemorrhage}

Diffuse alveolar haemorrhage is always a potentially life threatening situation and may be the initial manifestation of APS. ${ }^{59}$ Patients are usually middle aged and male and may present with symptoms such as ranging cough, dyspnoea, and fever with or without haemoptysis, progressing to symptoms of acute respiratory failure. ${ }^{60}$ The main laboratory features are hypoxaemia and anaemia, and chest radiography shows 
rapidly changing and extensive alveolar infiltrates. The diagnosis is one of exclusion and, as with other systemic autoimmune diseases, other causes of diffuse alveolar haemorrhage, such as uraemia, coagulopathy, pulmonary embolus, or infection, need to be excluded. Bronchioalveolar lavage may be useful in showing the presence of haemosiderin laden macrophages. Lung biopsy should only be considered if potentially diagnostic tissue cannot be obtained from any other site. ${ }^{61}$ Histopathologically, alveolar haemorrhage and microvascular thrombosis with or without pulmonary capillaritis are the main findings. ${ }^{125562}$ Almost all the patients who were treated with corticosteroids improved, regardless of additional treatment with cyclophosphamide. Therefore, the treatment of diffuse alveolar haemorrhage in APS should start with corticosteroids (usually intravenously at high dose-for example, l g methylprednisolone daily for three to five days) if the patient presents with severe respiratory distress. Two patients who did not respond to intravenous hydrocortisone and pulse methylprednisolone improved with plasmapheresis, ${ }^{963}$ and one patient improved upon institution of intravenous immunoglobulin treatment. ${ }^{59}$ If there is active bleeding it may be necessary to withhold anticoagulation, and to restart treatment as soon as the pulmonary status has improved. Another important point is the potential for relapse without immunosuppressive treatment, which occurred in three patients. ${ }^{59}{ }^{64}$ Thus a subset of patients may require long term immunosuppression, as is the case in other types of pulmonary capillaritis.

\section{Postpartum syndrome}

In 1986, Branch et al described, in several of their patients, a clinical picture consisting of spiking fevers, pleuritic chest pain, and dyspnoea, with chest radiographs showing pleural effusions and patchy infiltrates. ${ }^{13}$ Cardiac conduction defects were present in one patient. Another case with similar characteristics was described in 1994 by Kupferminc et al. ${ }^{65}$ A woman post partum developed fever, pulmonary infiltrates, cardiac conduction defects, and renal insufficiency after severe pre-eclampsia. She tested positive for LAC and aCL, and responded to steroid treatment and plasmapheresis. These cases may in fact be examples of microangiopathy and possibly catastrophic APS.

\section{Fibrosing alveolitis}

Only two case reports have reported the association of fibrosing alveolitis and APS until now. ${ }^{14}{ }^{66}$ The first report was of a man with definite primary APS who developed insidious diffuse pulmonary infiltrates. Histopathological examination of the lung showed alveolitis and fibrosis. The second was a patient with cryptogenic fibrosing alveolitis who developed pulmonary embolism and myocardial infarction in the presence of APS. Possibly, this rare association might simply reflect the concurrence of two entities in the same patient without a causal relationship between aPL and this condition.

In conclusion, patients with APS may develop a broad spectrum of pulmonary involvement, pulmonary thromboembolism and pulmonary hypertension being the most common complications described. In addition to these manifestations, patients with microvascular pulmonary thrombosis, pulmonary capillaritis, and alveolar haemorrhage have also been reported. Clinicians should seriously consider these types of vascular injury when evaluating patients with APS who present with dyspnoea, fever, and infiltrates on chest radiography. These conditions might occur as separate entities or may, in fact, form part of ARDS. Therefore, in the presence of these clinical features, clinicians must consider searching and testing for aPL when no other cause can be determined.

As treatment, long term anticoagulation is needed in all cases, at least to prevent the occurrence of new thrombotic events. There is not enough experience with immunosuppression in APS associated pulmonary hypertension. High dose steroids may be useful in the case of non-inflammatory vasculopathy (ARDS, pulmonary microthrombosis, and alveolar haemorrhage). The role of cyclophosphamide and other treatments, such as plasmapheresis or the administration of immunoglobulins, has not been well researched. The clinical setting will usually dictate whether additional treatments are required in these cases.

\section{ACKNOWLEDGMENTS}

Supported by grant FIS 1999/0280 from the Fondo de Investigaciones Sanitarias of Spain.

G Espinosa is a research fellow sponsored by grant FI/FIAP 1999/00684 from Comissió Interdepartamental per a la Recerca i la Tecnologia of Generalitat of Catalonia, Spain.

\section{Authors' affiliations}

G Espinosa, R Cervera, J Font, Department of Autoimmune Diseases, Hospital Clínic, Barcelona, Catalonia, Spain

R A Asherson, Rheumatic Diseases Unit, Department of Medicine, University of Cape Town School of Medicine and Groote Schuur Hospital, Cape Town, South Africa

\section{REFERENCES}

1 Greaves M, Cohen H, Machin SJ, Mackie I. Guidelines on the investigation and management of the antiphospholipid syndrome. $\mathrm{Br} J$ Haematol 2000; 109:704-15.

2 Asherson RA, Khamashta MA, Ordi-Ros J, Derksen RHWM, Machin SJ, Path FRC, et al. The "primary" antiphospholipid syndrome: major clinical and serological features. Medicine (Baltimore) 1989:68:366-74.

3 Font J, Cervera R, López-Soto A, Pallarés L, Bosch X, Ampurdanés S, et al. Anticardiolipin antibodies in patients with autoimmune diseases: isotype distribution and clinical associations. Clin Rheumatol 1989:8:475-83.

4 Wilson WA, Gharavi AE, Koike T, Lockshin MD, Branch DW, Piette J-C, et al. International consensus statement on preliminary classification criteria for definite antiphospholipid syndrome: report of an international workshop. Arthritis Rheum 1999;42:1309-11

5 Asherson RA, Cervera R. Review: antiphosphoslipid antibodies and the lung. J Rheumatol 1995;22:62-6.

6 Piette JC, Hunt BJ. Pulmonary hypertension and antiphospholipid antibodies. In: Khamashta MA, ed. Hughes syndrome. Antiphospholipid syndrome. London: Springer, 2000:96-104

7 Luchi ME, Asherson RA, Lahita RG. Primary idiopathic pulmonary hypertension complicated by pulmonary arterial thrombosis. Association with antiphospholipid antibodies. Arthritis Rheum 1992;35:700-5.

8 Ghosh S, Walters HD, Joist JH, Osborn TG, Moore TL. Adult respiratory distress syndrome associated with antiphospholipid antibody syndrome. Rheumatol 1993;20:1406-8.

9 Howe HS, Boey ML, Fong KY, Feng PH. Pulmonary haemorrhage, pulmonary infarction, and the lupus anticoagulant. Ann Rheum Dis 1988;47:869-72

10 Cucurull E, Ordi Ros J, Murtra M, Mellibovsky L, Orriols R, Vilardell M. Tromboendarterectomía pulmonar en un paciente con síndrome antifosfolípido primario. Med Clin (Barc) 1996;106:498-500.

11 Maggiorini M, Knoblauch A, Schneider J, Russi EW. Diffuse microvascular pulmonary thrombosis associated with primary antiphospholipid antibody syndrome. Eur Respir J 1997; 10:727-30.

12 Gertner E, Lie JT. Pulmonary capillaritis, alveolar haemorrhage, and recurrent microvascular thrombosis in primary antiphospholipid syndrome. J Rheumatol 1993;20:1224-8.

13 Branch DW, Kochenour NK, Rok NS, Scott JR. A new postpartum syndrome associated with antiphospholipid antibodies. Proceedings of the IInd International Symposium on Antiphospholipid Antibodies. London: University of London, 1986:3-10.

14 Savin $\mathbf{H}$, Huberman M, Kott E, Lishner M, Kitai Y, Kidron D, et al. Fibrosing alveolitis associated with primary antiphospholipid antibodies. Br J Rheumatol 1994;33:977-80.

15 Hillerdal G. The lung physician and the antiphospholipid syndrome. Eur Respir J 1997;10:511-12.

16 Brucato A, Baudo F, Barberis M, Redaelli R, Casadei G, Allegri F, et al. Pulmonary hypertension secondary to thrombosis of the pulmonary vessels in a patient with the primary antiphospholipid syndrome. $J$ Rheumatol 1994:21:942-4.

17 Turianski AA, Finkielman JD, Vazquez-Blanco M. Isolated tricuspid valve disease in antiphospholipid syndrome. Lupus 1998;8:474-6.

18 Khamashta MA, Cuadrado M, Mujic F, Taub NA, Hunt BJ, Hughes GRV. The management of thrombosis in the antiphospholipid-antibody syndrome. N Engl J Med 1995;332:993-7.

19 Muñoz-Rodríguez FJ, Font J, Cervera R, Reverter JC, Tàssies D, Espinosa $G$, et al. Clinical study and follow-up of 100 patients with the antiphospholipid syndrome. Semin Arthritis Rheum 1999;29:182-90.

20 Krnic-Barrie S, O'Connor CR, Looney SW, Pierangeli SS, Harris EN. A retrospective review of 61 patients with antiphospholipid syndrome: analysis of factors influencing recurrent thrombosis. Arch Intern Med 1997; 157:2101-8. 
21 Vianna JL, Khamashta MA, Ordi-Ros J, Font J, Cervera R, López-Soto A et al. Comparison of the primary and secondary antiphospholipid syndrome: a European multicenter study of 114 patients. Am J Med 1994;96:3-9.

22 Moser KM, Auger WR, Fedullo PF. Chronic major-vessel thromboembolic pulmonary hypertension. Circulation 1990;81:1735-43.

23 Jamieson SW, Auger WR, Fedullo PF, Channick RN, Kriett JM, Tarazi RY, et al. Experience and results with 150 pulmonary thromboendarterectomy operations over a 29 -month period. J Thorac Cardiovasc Surg 1993; 106:116-27.

24 Sandoval J, Amigo MC, Barragan R, Izaguirre R, Reyes PA, Martínez-Guerra ML, et al. Primary antiphospholipid syndrome presenting as chronic thromboembolic hypertension. Treatment with thromboendarterectomy. J Rheumatol 1996;23:772-5.

25 Asherson RA, Mackworth-Young CG, Boey ML, Hull RG, Saunders A Gharavi $A E$, et al. Pulmonary hypertension in systemic lupus erythematosus. BM 1983;287:1024-5.

26 Tam L-S, Li EK. Successful treatment with immunosuppression, anticoagulation and vasodilator therapy of pulmonary hypertension in SLE associated with secondary antiphospholipid syndrome. Lupus 1998;7:495-7.

27 Asherson RA, Hackett D, Gharavi AE, Harris EN, Kennedy HG, Hughes GRV. Pulmonary hypertension in systemic lupus erythematosus. A report of three cases. J Rheumatol 1986;13:416-20.

28 Mackworth-Young CG, Gharavi AE, Boey ML, Hughes GRV. Portal and pulmonary hypertension in a case of systemic lupus erythematosus: possible relationship with clotting abnormalities. Eur J Rheumatol Inflamm 1984;7:71-4.

29 Anderson EN, Ali MR. The lupus anticoagulant, pulmonary thromboembolism and fatal pulmonary hypertension. Ann Rheum Dis 1984;43:760-3

30 Asherson RA, Oakley CN. Pulmonary hypertension and systemic lupus erythematosus. J Rheumatol 1986;13:1-5.

31 Font J, López-Soto A, Cervera R, Balasch J, Pallarés L, Navarro M, et al. The "primary" antiphospholipid syndrome: antiphospholipid antibody pattern and clinical features of a series of 23 patients. Autoimmunity $1991 ; 9: 69-75$

32 Jeffrey P, Asherson RA, Rees PJ. Recurrent deep venous thrombosis and thromboembolic pulmonary hypertension in the "primary" antiphospholipid syndrome. Clin Exp Rheumatol 1989:7:567-9.

33 Alarcón-Segovia D, Sánchez-Guerrero J. Primary antiphospholipid syndrome. J Rheumatol 1989;16:482-8

34 Nagai H, Yasuma K, Katsuki T, Shimakura A, Usuda K, Nakamura Y, et al. Primary antiphospholipid syndrome and pulmonary hypertension with prolonged survival. A case report. Angiology 1997:48:183-7.

35 Alarcón-Segovia D, Deleze M, Oria CV, Sánchez-Guerrero J, Gómez-Pacheco L, Cabiedes J, et al. Antiphospholipid antibodies and the antiphospholipid syndrome in systemic lupus erythematosus. A prospective analysis of 500 consecutive patients. Medicine (Baltimore) 1989:68:353-65

36 Alarcón-Segovia D, Pérez-Vázquez ME, Villa AR, Drenkard C, Cabiedes J. Preliminary classification criteria for the antiphospholipid syndrome within systemic lupus erythematosus. Semin Arthritis Rheum 1992:21:275-86.

37 Petri M, Rheinschmidt M, Whiting-O'Keefe Q, Hellmann D, Corash L. The frequency of lupus anticoagulant in systemic lupus erythematosus. $A$ study of sixty consecutive patients by activated partial thromboplastin time, Russell viper venom time, and anticardiolipin antibody level. Ann Intern Med 1987;106:524-31

38 Miyata M, Suzuki K, Sakuma F, Watanabe H, Kaise S, Nishimaki T, et al. Anticardiolipin antibodies are associated with pulmonary hypertension in patients with mixed connective tissue disease or systemic lupus erythematosus. Int Arch Allergy Immunol 1993; 100:351-4

39 De la Mata J, Gomez-Sanchez MA, Aranzana M, Gomez-Reino JJ. Long-term iloprost infusion therapy for severe pulmonary hypertension in patients with connective tissue diseases. Arthritis Rheum 1994;37:1528-33

40 Asherson RA, Higenbottam TW, Dinh Xuan AT, Khamashta MA, Hughes GRV. Pulmonary hypertension in a lupus clinic: experience with twenty-four patients. J Rheumatol 1990;17:1292-8.

41 Wolf M, Boyer-Neumann C, Parent F, Eschwege V, Jaillet H, Meyer D, et al. Thrombotic risk factors in pulmonary hypertension. Eur Respir J 2000; 15:395-9.
42 Chaouat A Weitzenblum E, Higenbottam T. The role of thombosis in severe pulmonary hypertension. Eur Respir J 1996;9:356-63.

43 Cacoub P, Dorent R, Nataf $P$, Carayon A, Riquet $M$, Noe E, et al. Endothelin-1 in the lungs of patients with pulmonary hypertension. Cardiovasc Res 1997:33:196-200.

44 Atsumi T, Khamashta MA, Haworth RS, Brooks G, Amengual O, Ichikawa K, et al. Arterial disease and thrombosis in the antiphospholipid syndrome: a pathogenic role of endothelin-1. Arthritis Rheum 1998;41:800-7

45 Bayraktar Y, Tanaci N, Egesel T, Gokoz A, Balkanci F. Antiphospholipid syndrome presenting as portopulmonary hypertension. J Clin Gastroenterol 2001;32:359-61.

46 Hussein A, Trowitzsch E, Brockmann M. Pulmonary veno-occlusive disease, antiphospholipid antibody and pulmonary hypertension in an adolescent. Klin Padiatr 1999;21 1:92-5.

47 Haworth SG. Primary pulmonary hypertension. J R Coll Physicians Lond 1998;32:187-90

48 Auger WR, Permpikul P, Moser KM. Lupus anticoagulant, heparin use, and thrombocytopenia in patients with chronic thromboembolic pulmonary hypertension: a preliminary report. Am J Med 1995:99:392-6

49 Ando M, Takamoto S, Okita Y, Matsukawa R, Nakanishi N, Kyotani S, et al. Operation for chronic pulmonary thromboembolism accompanied by thrombophilia in 8 patients. Ann Thorac Surg 1998;66:1919-24.

50 Rich S, Kaufmann E, Levy PS. The effect of high doses of calcium-channe blockers on survival in primary pulmonary hypertension. N Engl J Med 1992;327:76-81

51 Humbert M, Sanchez O, Fartoukh M, Jagot JL, Sitbon O, Simmonneau $G$. Treatment of severe pulmonary hypertension secondary to connective tissue diseases with continuous IV epoprostenol (prostacyclin). Chest 1998;114(suppl 1):80-2.

52 Nakagawa $Y$, Masuda $M$, Shiihara $H$, Tsuruta $Y$, Abe $H$, Miura M, ef al. Successful pulmonary thromboendarterectomy for chronic thromboembolic pulmonary hypertension associated with anticardiolipin antibodies: report of a case. Surg Today 1992;22:548-52.

53 Kerr JE, Poe R, Kramer Z. Antiphospholipid antibody syndrome presenting as a refractory noninflammatory pulmonary vasculopathy Chest 1997; 1 12:1707-10.

54 Ware LB, Matthay MA. The acute respiratory distress syndrome. N Engl J Med 2000;342:1334-49.

55 Hillerdal G, Hagg A, Licke G, Wegenius G, Scheibenpflug L. Intra-alveolar hemorrhage in the anticardiolipin antibody syndrome. Scand J Rheumatol 1991;20:58-62.

56 Ingram SB, Goodnight SH, Bennett RM. An unusual syndrome of a devastating non-inflammatory vasculopathy associated with anticardiolipin antibodies. Arthritis Rheum 1987;30:37-42

57 Argento A, DiBenedetto RJ. ARDS and adrenal insufficiency associated with the antiphospholipid antibody syndrome. Chest 1998; 113:1136-8.

58 Asherson RA, Cervera R, Piette JC, Font J, Lie JT, Burcoglu A, et al. Catastrophic antiphospholipid syndrome. Clinical and laboratory features of 50 patients. Medicine (Baltimore) 1998;77:195-207.

59 Gertner E. Diffuse alveolar hemorrhage in the antiphospholipid syndrome: spectrum of the disease and treatment. J Rheumato 1999:26:805-7.

60 Specks U. Diffuse alveolar hemorrhage syndromes. Curr Opin Rheumatol 2001;13:12-17.

61 Crausman RS, Achenbach GA, Pluss WT, O'Brien RF, Jennings CA. Pulmonary capillaritis and alveolar hemorrhage associated with the antiphospholipid antibody syndrome. J Rheumatol 1995;22:554-6.

62 Asherson RA, Greenblat MA. Recurrent alveolar hemorrhage and pulmonary capillaritis in the "primary" antiphospholipid syndrome. J Clin Rheumatol 2001;7:30-3.

63 Waterer GW, Latham B, Waring JA, Gabbay E. Pulmonary capillaritis associated with the antiphospholipid antibody syndrome and rapid response to plasmapheresis. Respirology 1999;4:405-8.

64 Aronoff DM, Callen JP. Necrosing livedo reticularis in a patient with recurrent pulmonary hemorrhage. J Am Acad Dermatol 1997;37:300-2.

65 Kupferminc MJ, Lee M, Green D, Peaceman AM. Severe postpartum pulmonary, cardiac, and renal syndrome associated with antiphospholipid antibodies. Obstet Gynecol 1994;83:806-7.

66 Kelion AD, Cockcroft JR, Ritter JM. Antiphospholipid syndrome in a patient with rapidly progressive fibrosing alveolitis. Postgrad Med J $1995 ; 71: 233-5$ 